University of Wollongong

Research Online

Australian Institute for Innovative Materials -

Papers

Australian Institute for Innovative Materials

$1-1-2013$

One-pot green synthesis of Ag nanoparticles-decorated reduced graphene oxide for efficient nonenzymatic $\mathrm{H} 2 \mathrm{O} 2$ biosensor

Mingyan Wang

University of Wollongong, mingyan@uow.edu.au

Tao Shen

Huaihai Institute of Technology

Meng Wang

University of Wollongong, mw088@uowmail.edu.au

Dongen Zhang

Huaihai Institute of Technology

Jun Chen

University of Wollongong, junc@uow.edu.au

Follow this and additional works at: https://ro.uow.edu.au/aiimpapers

Part of the Engineering Commons, and the Physical Sciences and Mathematics Commons

Research Online is the open access institutional repository for the University of Wollongong. For further information contact the UOW Library: research-pubs@uow.edu.au 


\title{
One-pot green synthesis of Ag nanoparticles-decorated reduced graphene oxide for efficient nonenzymatic $\mathrm{H} 2 \mathrm{O} 2$ biosensor
}

\author{
Abstract \\ Ag nanoparticles (AgNP) with an average size of $12 \mathrm{~nm}$ are successfully decorated on the reduced \\ graphene oxide ( $\mathrm{rGO}$ ) sheets through a simple one-pot hydrothermal method using gallic acid as the \\ reducing agent. This AgNP/rGO hybrid has been successfully applied in the catalytic performance toward \\ the reduction of $\mathrm{H} 2 \mathrm{O} 2$. The nonenzymatic sensor demonstrates a linear relationship in a wide \\ concentration range of $0.05-5 \mathrm{mM}(\mathrm{R}=0.999)$, and a high sensitivity of $255 \mu \mathrm{Acm}-2 \mathrm{mM}-1$ to the detection \\ of $\mathrm{H} 2 \mathrm{O} 2$.

\section{Keywords} \\ oxide, efficient, nonenzymatic, h2o2, biosensor, reduced, graphene, decorated, one, nanoparticles, ag, \\ synthesis, green, pot \\ Disciplines \\ Engineering | Physical Sciences and Mathematics

\section{Publication Details} \\ Wang, M., Shen, T., Wang, M., Zhang, D. and Chen, J. (2013). One-pot green synthesis of Ag nanoparticles- \\ decorated reduced graphene oxide for efficient nonenzymatic H2O2 biosensor. Materials Letters, 107 (15 \\ September), 311-314.
}




\section{One-pot green synthesis of Ag nanoparticles-decorated reduced graphene oxide for}

\section{2 efficient nonenzymatic $\mathrm{H}_{2} \mathrm{O}_{2}$ biosensor}

3 WANG Ming Yan ${ }^{\mathrm{a}, \mathrm{b}^{*}}$, SHEN Tao $^{\mathrm{a}}$, WANG Meng ${ }^{\mathrm{b}}$, ZHANG Dongen $^{\mathrm{a}}$, CHEN Jun $^{\mathrm{b} *}$

$4 \quad{ }^{a}$ Department of Chemical Engineering, Huaihai Institute of Technology. Lianyungang, 222005, China

$5 \quad{ }^{\mathrm{b}}$ Intelligent Polymer Research Institute, ARC Centre of Excellence for Electromaterials Science, Australian Institute

6 of Innovative Materials, University of Wollongong, Northfields Avenue, Wollongong, NSW 2522, Australia

7 The contact details of corresponding authors:

8 WANG Mingyan: Phone: +86-518-85895409; fax: 86-518-85895401; mingyanlyg@ hotmail.com.

9 CHEN Jun: Phone: +61-2-42213781; fax: +61-2-4221 3114; junc@uow.edu.au.

\section{Abstract}

$12 \mathrm{Ag}$ nanoparticles (AgNP) with an average size of $12 \mathrm{~nm}$ are successfully decorated on the reduced 13 graphene oxide (rGO) sheets through a simple one-pot hydrothermal method using gallic acid as the

14 reducing agent. This AgNP/rGO hybrid has been successfully applied in the catalytic performance toward the reduction of $\mathrm{H}_{2} \mathrm{O}_{2}$. The nonenzymatic sensor demonstrates a linear relationship in a wide concentration range of $0.05-5 \mathrm{mM}(\mathrm{R}=0.999)$, and a high sensitivity of $255 \mu \mathrm{Acm}^{-2} \mathrm{mM}^{-1}$ to the detection of $\mathrm{H}_{2} \mathrm{O}_{2}$.

Keywords: Ag nanoparticles; green synthesis; reduced graphene oxide; nonenzymatic; sensor

\section{Introduction}

Silver is a well-known noble metal with high catalytic activity, remarkable optical properties, and excellent antibacterial activity [1]. Surfactants are usually introduced in the synthesis process for small Ag nanoparticles (AgNP) in order to avoid the conglomeration and large size of Ag particles, which could significantly depress its activity and stability [2]. However, the residual surfactant can also seriously deactivate the as-prepared catalyst. Therefore, the better method to prepare AgNP is on 
supporting materials, such as conducting polymers [3], carbon materials [4], mesoporous silica [5], and fiberglass [6], et al. Recently, graphene, as an ideal supporting material for the AgNP with large surface area and high electrical conductivity, has received significant attention. Byeong-Su $\mathrm{K}$ et al reported a green approach to synthesis of AgNP onto the surface of graphene oxide functionalized with mussel-inspired dopamine [7]. Won B K et al obtained uniformly dispersed AgNP on reduced graphene oxide by adding $\mathrm{NaBH}_{4}$ as reducing agent [8]. Pruneanu et al synthesized AgNP on few-layers graphene by radio frequency catalytic chemical vapor deposition [9]. Most developed methods still involved multi-steps and require strong reducing agents. It is still a challenging to develop a simple facile approach to effectively prepare AgNP decorated graphene hybrid with quality control.

In this work, we report an environmental friendly one-pot hydrothermal route to produce $\mathrm{Ag}$ nanoparticles decorated reduced graphene oxide hybrid (AgNP/rGO) using gallic acid (GA) as a reducing agent, which could be found in tea leaves, sumac, and other plants. The fabrication process is illustrated in Figure 1a. Firstly, $\mathrm{Ag}^{+}$ion was easily coordinated with negatively charged oxygen-containing functional groups on GO sheets. Followed by the hydrothermal process, $\mathrm{AgNP} / \mathrm{rGO}$ hybrid is obtained with the presence of GA. The as-prepared AgNP/rGO hybrid exhibits enhanced electrocatalytic performance toward $\mathrm{H}_{2} \mathrm{O}_{2}$ reduction and has been successfully applied for $\mathrm{H}_{2} \mathrm{O}_{2}$ detection.

\section{Experimental}

All the reagents are of analytical purity grade and have been received from commercial sources. GO was synthesized by the modified Hummers method [10]. The resulting GO solution was 
concentration of $2.5 \mathrm{mg} / \mathrm{mL} .1 \mathrm{~mL}$ of $50 \mathrm{mM} \mathrm{AgNO}_{3}$ solution and $60 \mathrm{uL}$ of $0.2 \mathrm{M}$ ammonia solution were dissolved into $30 \mathrm{~mL}$ distilled water for further use. $2 \mathrm{~mL}$ of $\mathrm{GO}$ was dispersed into the foregoing solution. The mixtures were added $6 \mathrm{~mL}$ of $5 \mathrm{mg} / \mathrm{mL}$ gallic acid solution and stirred for 20 min at room temperature then transfer in a Teflon liner of $40 \mathrm{~mL}$ capacity, and then the liner was sealed in a stainless steel autoclave. The autoclave was maintained at $190{ }^{\circ} \mathrm{C}$ for $5 \mathrm{~h}$ and then allowed to cool to room temperature by cool-water. Dark brown-colored precipitate was filtered off, washed with distilled water and absolute ethanol several times, and then dispersed in water for further use. Reduced graphene oxide without adding sliver salt was prepared by the same procedure for comparison.

The morphology and structure of the prepared samples were characterized by transmission electron microspcopy (TEM, JEOL-2010, voltage of $200 \mathrm{kV}$ ) and X-ray diffraction (XRD, D8-advanced, Bruker, $40 \mathrm{kV}, 20 \mathrm{~mA}, \mathrm{Cu} \mathrm{K} \alpha$ radiation). The atomic composition of AgNP/rGO was detected by X-ray photoelectron spectroscopy (XPS, Perkin Elmer, Al K $\alpha$ radiation). Raman spectroscopy was performed using a Jobin-Yvon HR800 Ram system.

All electrochemical experiments were performed on a CHI720 electrochemical workstation. Cyclic voltammetry (CV) and chronoamperometry (CA) testing were carried out using a 63 three-electrode cell, including a glassy carbon electrode (GCE) as the working electrode, an $64 \mathrm{Ag} / \mathrm{AgCl}$ electrode as the reference electrode, and a platinum wire electrode as the counter electrode.

65 For the working electrodes preparation, required amount of samples was ultrasonically dispersed in $0.081 \%$ Nafion solution to obtain a $2 \mathrm{mg} / \mathrm{mL}$ uniform ink. Then $10 \mu \mathrm{L}$ of the ink was dropped on the

67 GCE and dried in the air before the electrochemical tests.

\section{Results and Discussion}



the as-prepared GO is of a flake-like shape with slight wrinkles on the surfaces. From Figure 1c, it clearly shows that the rGO sheet has been decorated with Ag nanoparticles with an average diameter of $12 \mathrm{~nm}$. The existence of $\mathrm{C}, \mathrm{O}$ and Ag elements is further confirmed by EDS (Figure 1d). Si peak originates from the substrate. The corresponding particle size distribution is shown in Figure 1e, revealing AgNP with an average size of $12.29 \pm 0.12 \mathrm{~nm}$ dispersed on the rGO sheets. 2a). The as-synthesized GO displays a typical characteristic (002) peak at $10.8^{\circ}$. After the hydrothermal process, the diffraction peak (002) shifts to a higher angle at about $24^{\circ}$, which is ascribed to the reduction of GO sheets and restacking into an ordered crystalline structure. While the diffraction peaks of the AgNP/rGO are in good agreement with the standard Ag (JCPDS card: 04-0783) [11] except for the broad (002) peak at approximately $25^{\circ}$, which can be indexed as disordered stacked graphitic sheets [12]. No peaks from other phase have been detected, indicating that the product is of high purity. noted that GO exhibits a $\mathrm{G}$ band at $1603 \mathrm{~cm}^{-1}$, while the corresponding band of $\mathrm{rGO}$ and $\mathrm{AgNP} / \mathrm{rGO}$ are 1591 and $1590 \mathrm{~cm}^{-1}$, respectively. The red shifts of $\mathrm{G}$ band of $\mathrm{rGO}$ and AgNP/rGO can be attributed to the recovery of the hexagonal network of carbon in the rGO [13]. The chemical states of elements in $\mathrm{AgNP} / \mathrm{rGO}$ were further characterized by XPS measurements (Figure 2c) corresponding to the characteristic peaks of $\mathrm{C} 1 \mathrm{~s}, \mathrm{O} 1 \mathrm{~s}$ and $\mathrm{Ag} 3 \mathrm{~d}$. The XPS spectrum for Ag3d shown in Figure 2d exhibits two major peaks with binding energies at 368.2 and $374.3 \mathrm{eV}$, corresponding to $\mathrm{Ag} 3 \mathrm{~d}_{5 / 2}$ and 
silver [14]. The C1s XPS spectrum of GO (Figure 2e) could be deconvoluted into four peaks arising from $\mathrm{C}-\mathrm{C} / \mathrm{C}=\mathrm{C}(284.6 \mathrm{eV})$ in the aromatic rings, $\mathrm{C}-\mathrm{O}(286.4 \mathrm{eV})$ of epoxy and alkoxy, $\mathrm{C}=\mathrm{O}(287.8$ $\mathrm{eV})$ and $\mathrm{O}-\mathrm{C}=\mathrm{O}(289.3 \mathrm{eV})$ groups, respectively [15]. For AgNP/rGO (Figure 2f), the intensity of oxygenated groups decreased significantly, illuminating that GO was reduced to rGO during the hydrothermal process. The $\mathrm{C} / \mathrm{O}$ ratio of $\mathrm{AgNP} / \mathrm{rGO}$ is 11.2, four times higher than that (2.6) of GO. This result is in a good agreement with the results of Raman spectroscopy [15].

To assess the electrocatalytic performance of the as-prepared AgNP/rGO hybrid to $\mathrm{H}_{2} \mathrm{O}_{2}$, a nonenzymatic sensor was constructed. Figure 3a shows the CV curves of bare GCE, GO, rGO, and AgNP/rGO modified GCEs toward the electrocatalytic reduction of $\mathrm{H}_{2} \mathrm{O}_{2}$ in a nitrogen saturated 0.2 M pH 6.9 phosphate buffer solution (PBS). As shown in Figure 3a, AgNP/rGO exhibits a notable catalytic reduction current peak at $-0.43 \mathrm{~V}$ vs $\mathrm{Ag} / \mathrm{AgCl}$, while it exhibits no electrochemical response in the absence of $\mathrm{H}_{2} \mathrm{O}_{2}$, indicating the catalytic $\mathrm{H}_{2} \mathrm{O}_{2}$ reduction. In contrast, bare GCE, GO/GCE and rGO/GCE exhibited very poor activity to the reduction of $\mathrm{H}_{2} \mathrm{O}_{2}$ under identical conditions. All these observations reveal that AgNP/rGO exhibits notable catalytic activity for $\mathrm{H}_{2} \mathrm{O}_{2}$ reduction. Figure $3 \mathrm{~b}$ presents a typical steady response with successive addition of $\mathrm{H}_{2} \mathrm{O}_{2}$ at $-0.43 \mathrm{~V}$. As is shown in the low concentration range (the insert of Figure 3b), a quick amperometric response is observed within $5 \mathrm{~s}$ at $96 \%$ steady state current. This kind of $\mathrm{H}_{2} \mathrm{O}_{2}$ biosensor exhibits a linear relationship in a range from 0.05 to $5 \mathrm{mM}(\mathrm{R}=0.999)$ with a high sensitivity of $255 \mu \mathrm{Acm}^{-2} \mathrm{mM}^{-1}$. In addition, the detection limit is calculated to be about $0.01 \mathrm{mM}$ at the signal-to noise ratio of 3 . The relative standard deviation (RSD) of the current response to $1 \mathrm{mM} \mathrm{H}_{2} \mathrm{O}_{2}$ is $2.4 \%$ for 6 successive measurements.

111 Typical interferences using uric acid (UA), ascorbic acid (AA), dopamine (DA), and glucose (Glu) 
114 with high sensitivity and stability.

\section{Conclusion}

116 In summary, AgNPs with an average size of $12 \mathrm{~nm}$ have been successfully decorated onto the

117 rGO sheets through a simple one-pot hydrothermal method using gallic acid as the reducing agent.

118 The as-synthesized AgNP/rGO hybrid displays an excellent electrocatalytic activity toward $\mathrm{H}_{2} \mathrm{O}_{2}$

119 reduction, with a promising response.

\section{Acknowledgements}

121

122

This work was supported by National Natural Science Foundation of China (51202079 and 21201070). A project funded by the Priority Academic Program development of Jiangsu Higher Education Institutions. The authors are grateful to National College Student's Innovation Project and "blue and green blue project". Associate Prof. Dr Jun Chen also thanks ACES (Australia) for financial support on this UOW Inter-link project.

\section{References}

[1]Xiaoyan L, Feifeng W, Qinrong Q, Xingpin L. Liren X, Qinghua C. Mater Lett 2012; 66: 370-373

[2]Majid D, Ali KZ, Muhamad MR, Huang NM, Mohammad H. Mater Lett 2012; 66: 117-120.

[3]Uzeyir D, Murat K, Atilla C, Murvet V. Electrochim Acta 2012; 85: 220-227.

[4]Yi C, Tao W, Ding Z, Qianyi C, Changshan Z, Shuqing S, et al. J Phys Chem 2012; 116: 17698-17704.

[5]Panuphong P, Nagahiro S. Osamu T. Mater Lett 2011; 65: 1037-1040.

[6]Gordon N, Xuan L, Sharifeh M, Eric M, James E. Mater Lett 2011; 65: 1191-1193.

[7]Eun KJ, Eunyong S. Eunhee L, Wonoh L, Moon-Kwang U, Byeong-Su K. ChemComm 2013; 49: 3392-3394.

[8]Eun JL, Sung MC, Min HS, Youngmin K, Seonhwa L. Won BK. Electrochem Comm 2013; 28:100-103. 
[11]Panbo L, Ying H, Lei W. Mater Lett 2013; 97: 173-175.

138

[12]Kazuma G, Tara K, Eiji J, Aki Y, Hideki H, Takahiro O, et al. Caron 2011; 49: 1118-1125.

139

[13]Yupeng Z, Delong L, Xiaojian T, Bin Z, Xuefeng R, Huijun L, et al. Carbon 2013; 54: 143-148. 

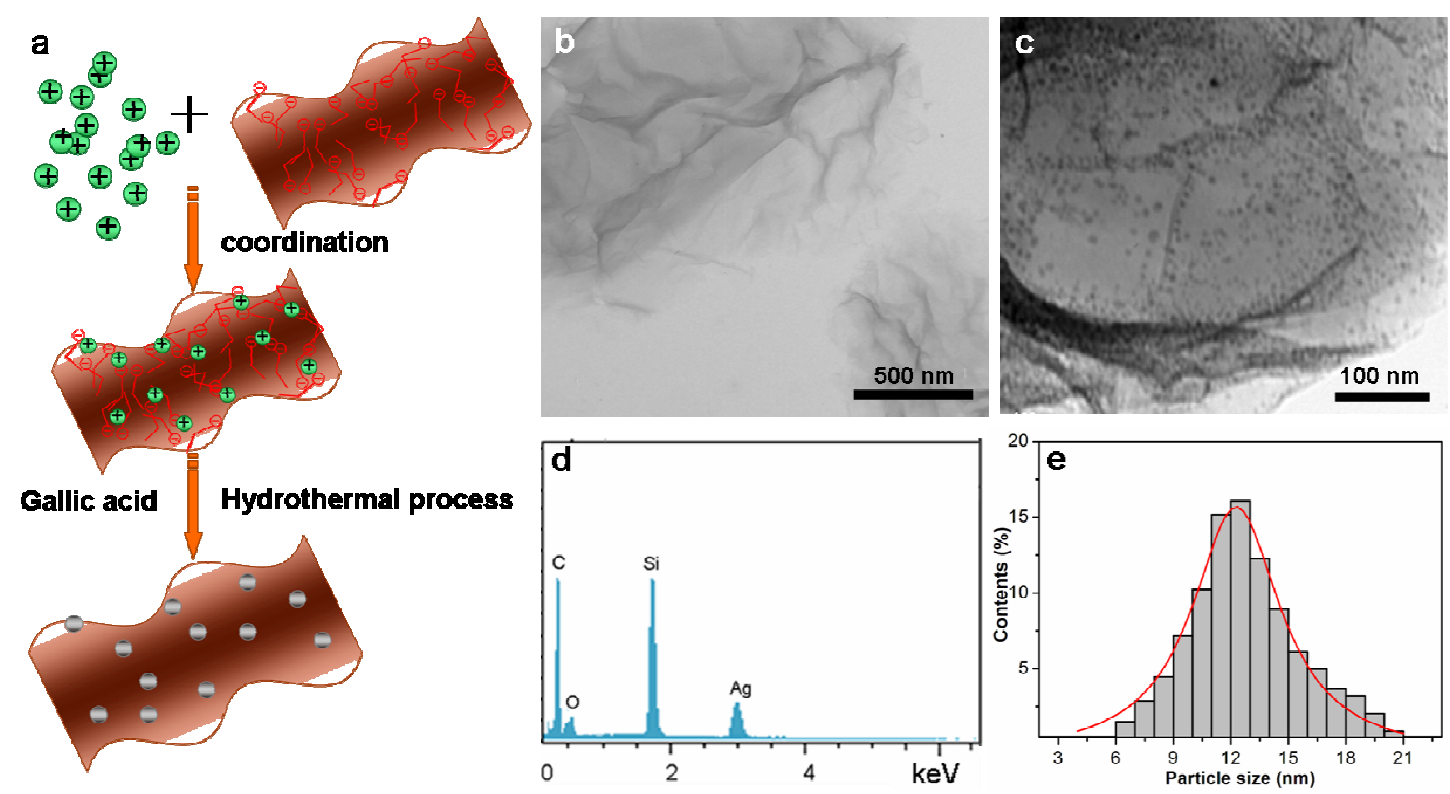

143

Figure 1. (a) A schematic for preparation of AgNP/rGO hybrid; (b, c) TEM images of the GO and 

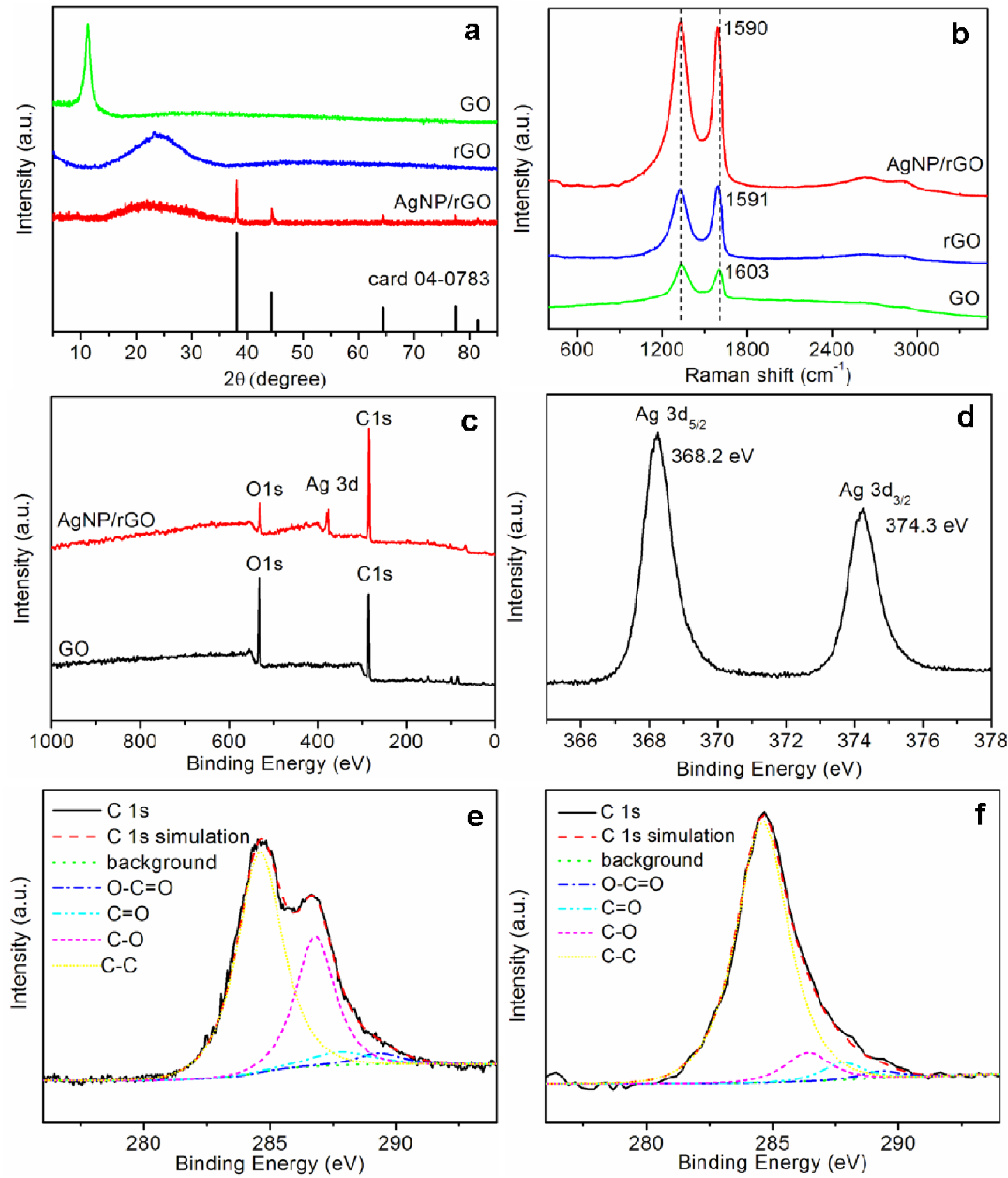

149

Figure 2. (a) XRD patters and (b) Raman spectra of GO, rGO and AgNP/rGO; (c) XPS survey

151 spectra of GO and AgNP/rGO. (d) Ag3d XPS of AgNP/rGO, (e, f) C1s XPS of GO and AgNP/rGO. 

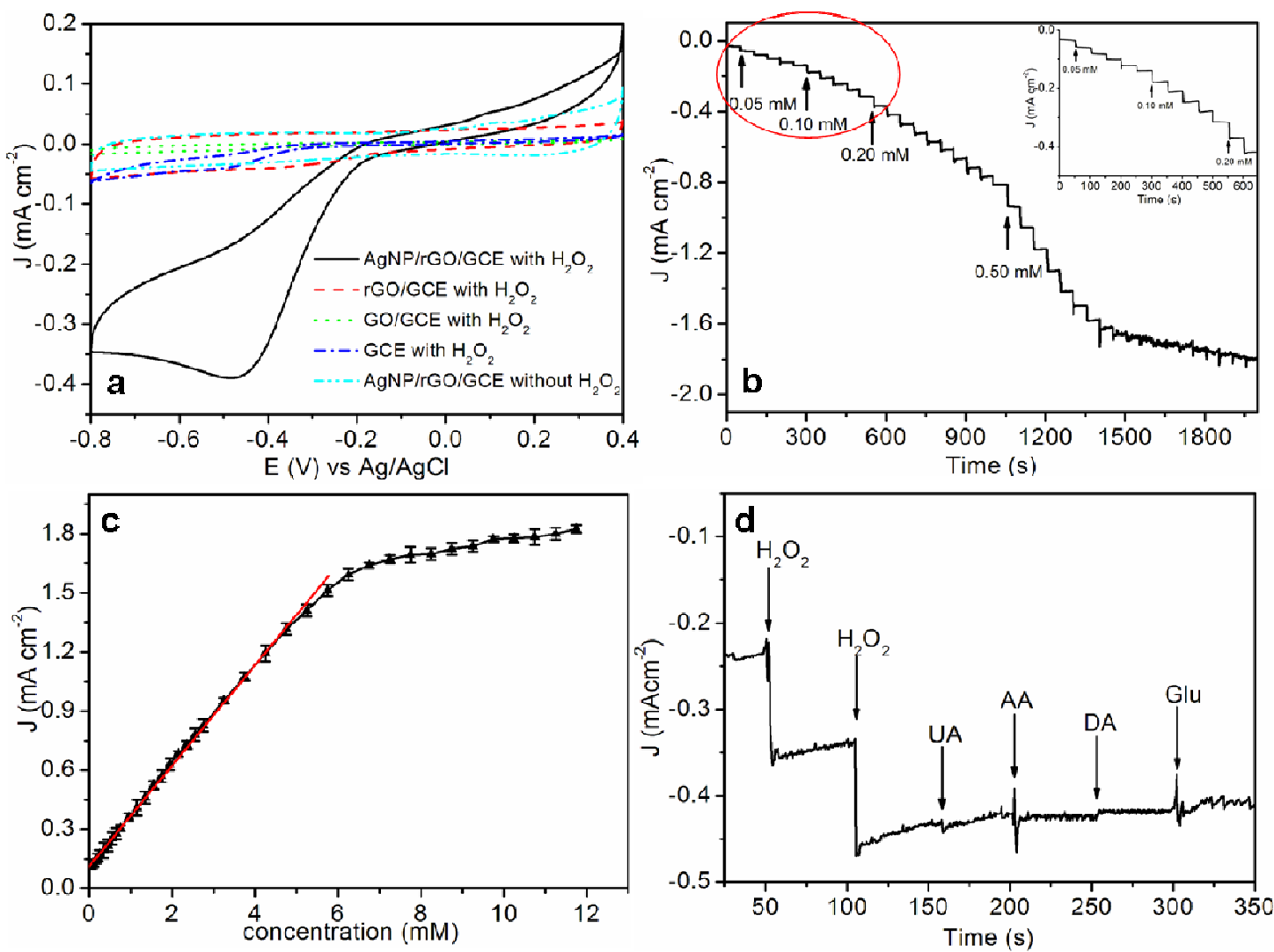

Figure 3 (a) CV curves of bare GCE, GO, rGO and AgNP/rGO modified GCEs in $0.2 \mathrm{M}$ PBS $\mathrm{N}_{2}$

saturated solution in the presence or absence of $1 \mathrm{mM} \mathrm{H}_{2} \mathrm{O}_{2}$; (b) Steady-state response of the

$\mathrm{AgNP} / \mathrm{rGO}$ to successive injection of $\mathrm{H}_{2} \mathrm{O}_{2}$ into $0.2 \mathrm{M}$ PBS $\mathrm{N}_{2}$ saturated solution; (c) The calibration curve of the reduction currents versus the concentrations of $\mathrm{H}_{2} \mathrm{O}_{2}$; (d) Current-time curve for the 